\title{
Changing Architectures and Evolving Urbanism in Modern Japanese Urban Environment
}

\author{
Raffaele Pernice
}

\begin{abstract}
The paper introduces some broad considerations on the relation between the process of urban growth and architectural development in modern Japan, which unfolded since the middle of the 20th century and heavily relied on new architectural ideas and models, and the progress of building technologies and infrastructure development staged during the year of rapid economic growth (1950s-1960s). It investigates how the urban environment which resulted was shaped according to the social, historical and cultural context of the country at the time, and was linked to some fundamental ideas derived from Western urban and architectural theories.

The fragmentation of the Japanese cites, which entered modernity earlier than other East Asian countries and witnessed first-hand the phase of surge and criticism of Modernism, have been influenced by the formation of a large extension of interconnected conurbations forming an intricate and dense urban structure, the so-called Tokaido Megalopolis, a continuous and integrated urban corridor stretching from Tokyo region to Fukuoka city.
\end{abstract}

Index Terms-Modern Japanese architecture, Japanese urbanism, Tokaido megalopolis, Tokyo, urban growth.

\section{INTRODUCTION}

In modern Japan the end of the Pacific War (1941-1945) promoted the resumption of the principles of the foreign matrix Modern Movement concepts in Japanese architecture. After the war Japan lay in a traumatic and shocked situation. The atomic bombs on Hiroshima and Nagasaki, the defeat of the national army and the consequent invasion by a foreign army were the beginning of a completely new era for the people of Japan. Together with the physical destruction of the cities arose a general feeling of despondency through society. Millions of people were without shelter due to the total or partial destruction of almost all cities. These were turned in a lunar landscape as deserts covered by the ashes of the burned houses. The urgency of fast reconstruction was evident from the very beginning, but the lack of building materials and economic support delayed the start of construction activity for several years. For this reason the government incited the population to start a self-reconstruction of their own houses for the entire period of early post war years. The selfreconstruction policy was intended as an effective solution to assure people obtained a house in a very short time, and in a way this helped in preserving the old city layouts with most of their rich historical urban frameworks. On the other hand it also prevented any improvement to the

Manuscript received November 2, 2013; revised February 11, 2014. Raffaele Pernice is with the Department of Urban Planning and Design, Xi'an Jiaotong - Liverpool University (e-mail: raffaeleitaly@ yahoo.com). dysfunctional precedent urban structure; most notably this retained the extreme fragmentation of the plots that will provoke many problems in the implementation of modern planning strategies during the fast industrial development of Japan in the next decade.

\section{Post-WAR JAPANESE ARChITECTURE AND URBANISM}

Because of the shock of the defeat and the general shortage of building materials, the main target of architects in the first years of peace time was the construction of safe shelters for the people. In order to tackle the need for fast re-construction, these years witnessed the development of various prefabricated systems for houses made of wood, whose main characteristics were both a very dense interior space and a fast and easy assembly. The theme of the prefabricated housing was to design-according to the Modernist concept of "existenz-minimum" (minimum living), a concept that recalls the design of interiors that fit the minimum dimensions for an acceptable standard of living, a feature that was also deeply embedded in the Japanese architectural tradition. Many houses designed during those years were very simple in plan because of the necessity to reduce the costs of production and the time of assembly. Furthermore the attempt to introduce a western style of life suggested using doors instead of shoiji or fusuma (sliding doors) in the separation of the spaces, and avoiding the use of tatami to cover the floors. Moreover, almost all the new houses had a dining-kitchen space, both to stress the more democratic current of Japan and to save more space in the tiny shelters.

In general terms until the early 1950s the shortage of building material such as steel and concrete, due to government rationing policy, caused the delay in the economic recovery and the lack of commissions from the private sector. In 1950 the outbreak of the Korean War was the main reason for the development of the Japanese economy, due to the investments from America which recognized the strategic geographical position of the Japanese archipelago. Indeed the consequence of this situation caused a strong flow of capital from the USA to Japan that in a short time helped to rebuild the Japanese economy. The large scale of industrial prefabrication of building elements became a standard procedure in the construction activity, and the most used material became reinforced concrete. At that time the main aim of the Japanese government was to develop and improve the infrastructure system of the country as well as to supporting the rebuilding of industrial systems. Consequently the cultural situation was suitable for a massive use of the principles of the Modern Movement in architectural design. 
These ideas were the best choice in that time for a functional architecture in behalf of a fast development of the whole Japan.

The complete transformation of Japan into an industrial and service sector based economy in a span of less than a decade caused a strong wave of migration of people from the rural areas and less developed regions to the cities in search of better shelters and jobs. This caused a fast and uncontrolled process of urban growth and transformation especially in the main urban conurbations along the Pacific Ocean, with progressive intrusion in previous agricultural lands and in general the alteration of their natural environment and the waterfronts, whose profiles were severely modified through land reclamation projects to gain space for new industrial facilities and housing estates.

By the early 1960s all plans for economic growth promoted by the government were completely fulfilled, in particular Prime Minister Hatoyama cabinet's "Economic Independent 5 Years Plan" (1955), the Kishi Cabinet's "New Long Term Economic Plan" (1957), and the Ikeda Cabinet's "Double National Income Plan" (1960-1962), thus Japan became one of the most dynamic and advanced industrial powers among developed countries [1]. The fast economic expansion accelerated the technological progress of Japan and the development of new modern infrastructures, and thus heralding an improvement of people's standard of life, with better alimentation and a general increase in the national wealth; on the other hand new serious problems arose as direct consequences of this fast growth, posing a severe threat to the social life of the citizens of the Japanese metropolises. Phenomena such as environmental destruction and the spread of several cases of diseases related to pollution in degraded urban districts were mainly caused by both the combination of poor city planning regulations and the evident priority given to economic growth over the citizens' welfare promoted by the central government.

In his investigations, Andre Sorensen noted the presence of ineffective instruments in the planning system in Japan was mainly the consequence of the central government's policy which aimed at a strong control over local authorities. Among the top priorities of the Japanese government there was the total support to the economic growth and the protection of public land and other urban areas from natural disasters, so that little efforts were put to relieve the shortcomings of this kind of city planning deregulation. In fact, until the late 1960s the Japanese zoning system counted for only 4 zones: residential, commercial, industrial and quasi-industrial, and "...within zoned areas land development was as-of-right, with no requirements for basic urban infrastructures before land development, no subdivision control, nor any minimum housing standards" [2]. Whereas by 1960 the worst cases of environmental contamination was basically due to the lack of governmental pollution standards and regulations. The presence of an high concentration of factories and industrial plants in the urban residential areas of the industrial cities resulted in more acute and dangerous levels of pollution for the citizens; this was due to the rapid uncontrolled urbanization of the post-war years and the fact that in Japan the industrial complexes tended to be located in small geographic areas as integrated clusters of interrelated industries close to each other and to the workers' residential areas. Furthermore the pace of accelerated urban growth and the fast urbanization of large rural lands generated a massive extension of disordered areas and uncontrolled urban sprawls in the outskirts of all the industrial cities, which caused 2 main problems: the chronic shortage of many public services and facilities faced by the growing number of their residents (such as the lack of parks and libraries, inadequate roads, sewers and water supply systems), and the awareness that the inefficient land use in the vast extensions of congested and undeveloped/unplanned urban areas created serious obstacles for any attempt of further improvement and urbanization according to rational plans, because of the higher costs to be paid for the construction of the infrastructures and the lack of space for effective improvement works [3].

Indeed the urban sprawl in the early 1960s became a serious concern to the Japanese government, which traditionally retained a narrow view of the urban planning approach (toshi-keikaku), intended as a simply process of supplying public infrastructure as functional and necessary elements to sustain the process of economic and urban growth (and for that reason of exclusive competence of bureaucrats, technicians and engineers), and with little attention to issues related to the environmental embellishment and the quality of the urban life of the citizens. The Japanese planning approach was the mainly based on the implementation of the land readjustment practice (kukaru seiri), a key planning instrument in Japan since the Kanto Earthquake which hit Tokyo in 1923[4].

The consequences of this tremendous mix of ineffective building standards, an inconsistent city planning approach and political unwillingness caused the fast, chaotic and largely unplanned development of vast low quality urban areas in the main industrial districts of Tokyo, Osaka, and Nagoya. This created a set of specific and less specific issues concerned with the expansion of the urban model of industrial metropolis, especially regarding the problem of housing shortage, which called for a rapid and effective response.

\section{LOW COST HOUSING IN JAPAN}

In 1955 the JHC -“Japan Housing Corporation”- was established as the state agency for the development and construction of apartments and other housing facilities in the main metropolitan areas. Its main task was the resolution of the tremendous housing shortage which year after year became worse due to the massive migration of populations from the small towns in the countryside into the large industrialized metropolitan areas. The master-plan and the organization of the new towns and new developing suburbs were mainly structured as "kombinato", an urbanworking unit which gathered large factories and extensive housing complexes (danchi). These ones were designed as groups of buildings, mainly 4 floor high, called "kodan jutaku", typically 2DK (2 rooms and a Dining-Kitchen) apartment units made of reinforced concrete and built mostly by semi-public agencies. 
The scarcity of land within the city suitable for new buildings and their soaring costs suggested the JHC develop large scale danchi in suburban areas where the prices were lower, and usually along public and private railways lines, targeting middle-income employees of enterprises in the major cities. This situation led to the further investments in the development of the infrastructures necessary to support the growth of peripheries in terms of transportation and power, and prompted the design and the construction of low cost housing units, which fostered research about new building materials (during those years many new buildings were built in concrete instead of wood) and techniques, based especially on the industrial prefabrication processes [5].

The main target of housing policy enacted by the Japanese government during all the decades from the 1950s to the 1960 s was the resolution of the housing shortage in all areas of Japan, a goal that was successfully achieved in the early 70s and hailed as a "housing miracle", which, as in the case of post war reconstruction of France, Germany and other European countries, revealed the construction sector as one of the main engines which recovered the economy of Japan and proposed housing as an instrument of national economic regeneration [6]. The main consequence of this housing policy, in spite of the important results achieved in terms of quantity, was, however, limited space and (often) extremely low quality of housing interiors when compared with Western standards, motivated by economic, cultural as well as anthropological factors, such as the shorter stature of the Japanese [7]. In any case, the issue of the small dimension of the houses was above all a necessity justified by economic reasons, such as the shortage of building materials, although it was also a feature deeply rooted in Japanese culture. Several architects were engaged in the design of low-budget houses for mass production by means of prefabricated industrial elements. The architectural and urban projects developed in this period followed this design approach inspired by the studies conducted by European Functionalists in the 1920s, and reflected the general awareness of the need of architectural standardization oriented to the mass production of low-cost housing based on industrial production. In particular the search for new forms of the modern residential typologies and interiors, inspired by the concept of privacy and comfort which was taken from the Western style of life, proved to be among the most challenging issues for the Japanese architects in search of a balanced combination of elements from different cultural worlds. The huge improvement of the quality of life in the cities fostered the awareness of the necessity of a new organization of the interior spaces of the house and the domestic spaces. Thus the cultural revolution that was occurring in the Japanese society at the time, first of all the advancement of the social position of the Japanese women, promoted the study and the development of new residential typologies which emphasized the clear separation of functions: separated bedrooms for the members of the family (both for the couple and children) and the separation of the functions of eating and sleeping spaces. This was in order to give a new sense of dignity to the separated work activities in the house and at the same time to stress the passage from the pyramidal hierarchical order of the traditional family to the democratic values of the modern times [8]. New standards for housing were set to face those changes. One prominent transformation in the house to reduce women's work and assure a more functional arrangement of the living spaces was the introduction of the DK (dining-kitchen) unit, which promoted the new concept of separation of sleeping and eating areas inside the Japanese house, which until then occupied the same space [9]. It is interesting to note that a DK housing unit could be considered as the Japanese evolution of the famous prototype of a compact and functional kitchen system developed in Germany by the Bauhaus during the 1920s, known as "Frankfurt-kitchen". The Japanese housing unit had several versions in the following years, with the most common type as a 2DK, or two rooms and a dining-kitchen space, designed during the 1950s and the 1960s [10]. The lay-out of this compact housing unit soon became the basic standard for both public and private residential architecture, although the small size of the rooms continued to be the main handicap in all the models [11].

The recovery of the economy proceeded faster and faster during the entire second half of the 1950s and the next decade, and this situation produced a growing sense of optimism and a strong orientation toward private consumerism which of course also influenced the search for more comforts and improvement in the house. Among the many manufactured goods that caught the interest of Japanese people was the television set, which by1962 was owned by $45 \%$ of all households (television was first broadcast in 1952). Some scholars have observed that: "The 'three sacred treasures' of Japan, anciently the mirror, the jewel, and the sword, became in the late 1950s the television, the refrigerator and the washing machine. In the early $1960 \mathrm{~s}$ a new set of consumer 'treasures' were designated the 'three C's', the car, the color television, and the 'room cooler', and by the late 1960's there were the 'three V's', the villa, the vacation, and the visit to a foreign country. The Japanese media described the new privatistic orientation toward home and possession as 'my home-ism' and my 'car-ism' [12]". One of the main consequences for this tendency of Japanese people toward the possession of their own house, together with the issues of the building costs and the need for a reasonable length of construction time, was the extraordinary development of research in the field of modular coordination.

The studies on the modern modular coordination in the 1950s undertaken in Japan, led the young Japanese architects to deepen their knowledge about similar activities of European colleagues, especially by Le Corbusier and his studies about the concepts of "modulor", standards and prefabrication. That these subjects became extremely important to Japanese architects and the construction industry sector was well evident in an editorial written in the magazine Kokusai-Kentiku by Tanabe Kazuto in 1958, who pointed out that: "After the war, around the year 1950, there began the work of reconstruction of destroyed cities, requiring a great number of responsible architects, naturally lending itself to the revival of the study of modular coordination [which in Japan started in the years prior the World war II]. What was most shocking in this period of time was the introduction of "Le Modulor" by Le Corbusier. 
The Le Corbusier idea immediately caught the attention of groups of Japanese architects. It was just at this time that others began to re-examine the module in system Japanese wooden architecture, with a view to improving it into a more modern shape. And there were still others who devoted themselves to a study of a new module, from their own point of view. However, it took some time before individual scholars were called upon to engage in joint studies on this subject" [13]. This orientation was further reinforced by a general sense of awareness of the necessity to protect the traditional culture and the sense of national identity, and to stop the frantic process of transformation of the urban environment that was occurring during recent years. Many surveys of old buildings and other research projects were implemented from the middle of 1950s and new laws were proposed aimed at the protection and preservation of antiquities [14]. Architects and critics such as Kenzo Tange and Noburo Kawazoe contributed to the improvement of the knowledge of traditional architecture by publishing in 1961 an influential book titled "Ise: Prototype of Japanese Architecture," emphasizing the superb centennial tradition of Japanese carpentry and its sense of proportion and the modernity of its technological approach in the design, in a period that in a few years witnessed a growing interest for the traditional architecture design and for the ancient Japanese cities, as can be seen from the publication in 1968 of the important essay "Nihon no toshi kakuen" (The Japanese Urban Space), edited among the others by Arata Isozaki and Ekuan Kanji [15].

Manfredo Tafuri noted that Le Corbusier's theories and projects were the main reference and source of inspiration for the new generation of Japanese architects, especially because of his search for ".... a quality into the standard and the symbolic value of architecture" [16], so that the great European master became the catalyst of creative autonomous forces inside the modern Japanese architecture, in particular through the aesthetic inspiration spread by his later works [17]. Hence the new post-war Japanese architecture derived from a process of evolution and further development of several factors, above all the improvement of technological housing standards and the search for a modern language which bound the architectural influence of International style with the repertory of traditional architectural forms and building techniques.

\section{Technology AdVAncements In the Post-WaR CONSTRUCTION SECTOR}

A very important point in the phase of rebuilding Japan was the issue of technological innovation pursued by Japanese companies and sponsored by the government, so that it was possible to fill the gap with the products of foreign countries and restart the economy of the nation. The importance of the role of the Japanese central government has been noted, especially during the 1950s when they continued a policy which had been fruitful at the time of the Meiji epoch, in which Japan fostered the modernization of the country by importing knowledge and competences from other Western industrial nations.

The Japanese government indeed had special merits in the development and success of the thriving building companies in the post-war years. In his research about the relation between architecture and authority in Japan, the scholar William Coaldrake stressed that the two main characteristics of the past half century were the importance of the construction sector as a fundamental element in the growth of GNP, and the dominance of the cities as main concentrations of people, capitals and activities [18]. Hence it can be said that both the development of modern industrial technology (supported by many members of the Japanese industrial system) and the growth of extensive metropolises, whose extension and density were unknown to the rest of the world, were among some of the main characteristics that shaped modern Japanese culture and urban environment in those years.

The combination of advanced systems of research and production, and the high concentration of people in limited and compact areas became a mix which fostered the development of radical and innovative solutions, both in the technology used and in the aesthetical forms; the urban development and the building activity had a such high pace during that period that the construction industry accounted for $30 \%$ of the total gross expenditure of Japan, becoming the foundation of Japanese economic growth and one of the main industries of the country, a trend continued for many decades since [19].

One of the most important achievements during those years was the progressive construction of rental apartment house complexes (danchi), which the government sponsored as the typical housing complex for the urban working class. The spread of this typology of mass housing accelerated in the second half of the 1950s, when throughout the country there was the spread of high rinse multi-unit dwellings blocks in the suburbs of the main cities (mostly built by the Japan Housing Corporation after 1955) and in the planned new towns. Even though some criticism arose about the small size of the apartments, the overall space was larger in comparison with those of the apartments built by private firms, and also the quality of the interiors was better due to the improvement of some facilities, such as the kitchen sink, which introduced higher standards of comforts [20].

The private firms were capable of satisfying public demand for better quality and cheaper housings with the development of prefabricated single family houses and condominiums (named "mansions"), but had to face many obstacles present in the Japanese cities, in particular the overcrowded spaces, the small dimension of lots of land, as well as the limitations and annoyances posed by many legal restrictions (such as those regarding the property of land and the fire codes). The efforts to overcome these problems and compete on a very competitive housing market encouraged the construction companies to improve their technologies and develop new design methods suitable to be inserted in a difficult urban environment. In this sense several construction companies developed new residential typologies to face the problem of the shortage of buildable land and the creation of attractive homes and apartment houses for the market, which mostly preferred single family houses. This resulted in a spread use of new residential units designed with courtyards, pilotis, open wells and core systems. According to Inabe and Nakayama: "Houses and apartments with courtyards are eminently suitable to city 
life in that they incorporate light, air and an outside view while maintaining the privacy of the inhabitants. Houses or offices raised on pilotis or stilts make advantageous use of limited lots by creating open space beneath the structure that can be put to various uses. Houses with open wells spanning to several floors can create a sense of unconfined space that would otherwise be difficult in a small structure; skylight at the top of the well can also introduce light and promote the aura of expansiveness. Structure employing a core system - whether homes or office buildingsconcentrate certain facilities in one area for economical construction or for protection against earthquakes and fire" [21].

The constant risk of potential disasters (which means severe restriction in the application of the building codes) and the consolidated social and cultural norms of living in detached houses which form clusters of self-regulating neighbourhoods have shaped the typical Japanese urban landscape. This is organized as a dense system of low-rise, enclosed communities of fragmented mixed-used urban entities built around the rojo (narrow alleyways), which is the main stage of the daily life of the traditional district and of the new residential area as well. Indeed this is one of the main characters that typically shape the townscape and the fine urban tissue of Japanese cities which form the vast conurbations along the archipelago.

The Japanese government directly stimulated the research in the field of advanced building techniques and the development of more economical solutions to housing problems by means of design competitions. To make these competitions more interesting (such as the "Pilot House Project", undertaken in 1970 as an experimental project for the design of single-family and multi-dwelling systems to be built in a new town, and the "Ashiyama High-Rise Housing Competition," held in 1973, for the construction of high-rinse apartment units to be built on the reclaimed land in the suburb of Osaka) for the construction companies was the fact that competition winners were awarded building contracts by the Japan Housing Corporation [22]. Indeed several researches and investigations were conducted in the field of building technology for the development of various efficient and economical construction systems to be used in the development of the dwellings of the spreading new urban communities, and those researches were generally promoted and financed by national universities, public agencies, private firms and industrial companies.

\section{THE FormATION AND DEVELOPMENT OF A SUPER- Cluster of Cities: THE Megalopolis of TOKAIDO}

According to Norman Glickman's analysis on the evolution of post-war Japanese cities, the Japanese tendency towards urbanization from the 1950s to the 1970s followed a pattern based on four main phenomena: the first was the concentration of population and economic enterprises in the central region of the archipelago, along the coastal region of the Pacific slope from Osaka to Tokyo, note currently as "Megalopolis of Tokaido", a name that recalls the ancient route which connected Kyoto to Edo (Tokyo) and that refers to a new type of urban structure theorized during the 1950s by the scholar Jean Gottmann, who studied the dense urban conurbation developed along the Washington-Boston corridor in the East Coast of the US, characterized by high density, extension and concentration of function, activities and wealth [23]; the second was a phenomenon of emigration of rural masses toward the region of the Tokaido (named as process of "centralization", with the growth of the core of the big cities), particularly in the years between the 1950 s and the 1960 s, followed by a relative emigration from the big industrial centers in the suburbs (called a phase of "suburbanization", with the growth of the main urban peripheries) during the 1970s; the third phenomenon was a following stage of further development of the suburbs in consequence of a phase of delocalization of population and activities in the surrounding areas of the big metropolitan centers. And a fourth and final factor was the progressive surge of further cases of congestion and pollution episodes in the large cities [24].

After 1955 the economic growth of Japan was one of the highest among the most industrialized countries. In this period the GNP reached values of around $9 \%$ annual at the end of the sixties, much superior to that recorded from developed western countries. Actually the economic growth will truly become the engine that will push the growth of Japanese urban development. The fast and complete transformation of the Japanese economy from a mainly primary sector to secondary sector promoted the transformation of the traditional country-based rural society to an industrial urban-based society. In 1950 about $48 \%$ of working Japanese population was engaged in agriculture, fishing and forestry occupation, and in 1960 this share became 32, 5\% [25]. In 1955 the government led by Prime Minister Hatoyama's administration proposed a long term national economic plan which aimed to achieve economic independence and full employment throughout Japan; these targets were completely fulfilled in just 2 years, hailing the official conclusion of the post-war period.

Therefore at the end of the 1950s a phase of rapid and dramatic transformation of the organization of the economy started, representing the change from a primary industry to secondary-tertiary sectors. This transformation determined an abrupt change of the distribution of the population and the working activities in the territory (as mentioned previously), particularly concerning the industrial factories, which since then are gathered in the area between Tokyo and Osaka (the Tokaido region). As the incomes of the workers of that area will become soon the highest of Japan, the need of workers, together with the attraction of higher salaries, this prompted an enormous mechanism of emigration from the rural areas toward the industrial metropolises in reconstruction, located in the heart of the country. The inevitable consequence of this mechanism was the depopulation of several rural areas of Japan and the growth of the large industrial cities, whose urban development continued a trend that had already delineated in the 1920s [26].

Between the end of the 1960s and the beginning of the 1970 s, the wave of emigration that had re-shaped so much quickly and heavily most of the main Japanese metropolitan areas had stopped, substantially transforming the urban landscape of Tokyo, Osaka and Nagoya, which constituted the core of Tokaido Megalopolis. The growth of 
metropolitan areas led to some important structural changes of the society promoted by a drastic reduction in the proportion of the population employed in the primary industries (agriculture and fishing) together with a simultaneous strong emigration from a rural context to an urban environment in a fairly short temporal span if compared with analogous experiences in the western countries. This structural transformation, according to the scholar Norman Glickman, had at least 3 important consequences in the Japanese regions. First, it carried out a notable depopulation of many rural areas and these areas (around a $1 / 3$ of the whole Japanese territory) were unable to sustain their economies and to guarantee a decent income to their populations, composed primarily from workers in the agricultural field. Second, there was contemporarily an overcrowding of the big cities that determined (in many cases) the well-known phenomena of pollution and congestion. Moreover, there was an increasing fracture between the rich regions based on industries and those poorer rural areas. These plans essentially consisted of the adoption of a policy of urban decentralization, through the design and construction of new towns based on the presence of local industrial complexes (NICs) and the creation of special areas of development (SASs), a program pursued together with the development of an impressive series of public infrastructures as roads, harbours, artificial basins, etc.; contemporarily the government decided the start of a policy of taxation and programs of benefits to help the less developed regions.

Most public investments were poured in the central Tokaido region and the economic development was encouraged in that area with all the means, particularly by installing heavy industries factories (production of steel, petrochemical and naval industries). In other words the goal of the Japanese government was to integrate and strengthen the economy of the urban areas which saw the highest concentration of industrial factories and other productive structures. Searching for means to coordinate and control the fast expansion of the urban areas of the archipelago, one of the first architects who proposed a comprehensive urban plan for the expansion of a contemporary mega-city (Tokyo) in the early 1960s, based on the precise and rigorous economic and technical analysis, was Kenzo Tange. In his plan to transform the Japanese archipelago in a huge urban network of cities and conurbations interconnected by fast bullet trains along the Japanese archipelago, he promptly recognized that such new urban structure could not be planned using the methodologies elaborated by modernist architecture and focussed on the simple tools of a master plan and zoning. Underlining the importance of factors such as the flexibility and the transformability inherent of the urban settlements of 10 thousand or more persons, he was undoubtedly among the architects who widened the concept of city, adjusting it to the contemporary scale of enormous social and technological transformations that occurred in the second half of the $20^{\text {th }}$ century. Scholar Steward noted that was the influence of Kiyonori Kikutake's projects, one key founder of the Japanese metabolist group, that fostered the awareness of Tange about the necessity for an urban planning for the masses, conceived by means of mega-structures and other hyper-technological devices [27]. According to Tange the huge scale of the mega-city was not an evil, or something to be rejected a priori, but somewhat the natural consequence of the economic transformations and the technological development in contemporary society. Therefore he envisioned the mega-city essentially as an organization that sustained the activities of the tertiary industries (services and distribution of goods), and it was the natural consequence of the radical economic transformation that from 1955 and for all the next decade, promoted the passage from a society economically based on agriculture to another, based initially on the industry (secondary activity) and then on the tertiary activities.

Later in the 1960s, following his studies on the socioeconomic and urban development in post-war Japan, he proposed the vision of the development of the whole nation as a single highly evolved urban organism: the "Tokaido Megalopolis". With this word he conceived the Japanese archipelago as a whole immense and continuum urban extension, with a much more sophisticated inner structure, rejecting again the satellite-town scheme proposed by the government as reference for main model of the Japanese urban system. From his analysis on the objective fact that in Japan the persons and capitals had been assembled in the Tokaido region mainly around the urban poles of Tokyo, Nagoya and Osaka, he developed a scheme based on a territorial organization that presents a structure in shape of "ribs and backbone". He created his scheme based on the massive development of an intricate and highly advanced network of road and railway connections with the purpose to strengthen the bond between these pivots of the system. The purpose was clearly to strengthen the flow of persons and commodities inside the national territory, based on a system of transportation which could guarantee efficient and rapid communications among the most developed areas of the country [28].

\section{CONCLUSIONS}

Transcending the consideration on the aesthetics of the architectural styles and typologies and focusing more on the attention of the functionality and efficiency of the urban machine, which were the priority of Kenzo Tange's project for a Japanese super urban region, it is important to note as the constellation of Japanese cities which form the Megalopolis of Tokaido is a complex urban framework that under the present economic and social systems constitute an extremely efficient and dynamic urban region on a global scale. The geographer Yasuo Masao stressed the importance of the development of transportation systems in the metropolis of Tokyo especially after the Pacific War, and described this megalopolis as a huge and interconnected "rail-road city", which is characterized by mixed land use and high density of inhabitants (because "... [its] residents must live near the stations"), who make full use of mass public transit systems [29], and indirectly confirmed the reality of the phenomenon of "megapolitanization" of the Japanese urban environment which, even though in different forms due to different historic and cultural background, has begun to emerge elsewhere and especially in other Asian nations as an effective way of expanding a city in the 
second half of $20^{\text {th }}$ century. Despite the shaping of the modern Japanese city was influenced by several Western theories of architecture and planning, nonetheless Japan has assumed a leadership position in the search for new directions in architectural and urban theories (balancing the conflict between traditional and local values with international and external influences) by the end of the last century.

The skylines made of several new urban redevelopment projects, essentially main local urban centres composed of clusters of iper-technological tall office towers and public multifunctional buildings linked with a minority of high rise residential complexes nearby, define a contemporary urban environment emanating a sense of "island" landscapes, whose view can be described as scattered "archipelagos" of massive landmark blocks floating on a vast sea of low-riselow-density constructions, mostly formed by residential areas. As also pointed out by the German historian Gunter Nitschke, in the 20th century Japan exerted a strong influence also into the development of new forms of cities. In his view "... The Japanese city of today is largely a haphazard, interchangeable mosaic of postage-stamp land parcel that seem rather messy form the view point of classical aesthetics. Yet it is hygienic, efficient and very adaptable to rapid change, and hence an important underpinning of the world's second largest economy... While the masses indeed sleep in "rabbit hutches" they work and play in cities that have no equal anywhere for liveliness, visual complexity and social dynamics [30]".

The integrated urban system of Tokaido Megalopolis shows exactly the validity and success of this new model of urban growth populated by modern "urban nomads", under many aspects different from similar Western models, and with many unique features; it proves to be a success for the Japanese model of multi-polar urban growth and space design structuring which is related in special way to the concepts of transience and impermanence, as transcendent ideas deeply rooted in the traditional culture and lifestyle of Japan.

\section{REFERENCES}

[1] S. Takegawa, "The Development of Regional Social Planning in Postwar Japan," presented at the ISA Research Committee 19 Meeting, Copenhagen, Denmark, 1997.

[2] A. Sorensen, "Building world city Tokyo: Globalization and conflict over the space," The Annals of Regional Science, cfr. A. Sorensen, The Making of Urban Japan. Cities and Planning from Edo to the Twenty-first Century; London \& New York: Nissan Institute/Routledge Japanese Studies Series, Berlin: Springer-Verlang, vol. 37, no. 3, p. 523, 2002.

[3] A. Sorensen, "Building world city Tokyo: globalization and conflict over the space," The Annals of Regional Science, Berlin: SpringerVerlang, vol. 37, no. 3, p. 523, 2003.

[4] A. Sorensen, The Making of Urban Japan. Cities and Planning from Edo to the Twenty-first Century; London \& New York: Nissan Institute/Routledge Japanese Studies Series, Ed. London: Palgrave Macmillan Ltd, 2003.

[5] A. Waswo, Housing in Postwar Japan. A Social History, London: Routledge, 2002, p. 57.

[6] A. Waswo, Housing in Postwar Japan. A Social History, London: Routledge, 2002, pp. 57-59.

[7] R. Boyd, New Direction in Japanese Architecture, New York: George Braziller, 1968, p. 13.

[8] A. Waswo, Housing in Postwar Japan. A Social History, London: Routledge, 2002, p. 68.
[9] K. Inabe and S. Nakayama, Japanese Homes and Lifestyles. An Illustrated Journey through the History, Tokyo: Kodansha International, 2000, p. 116.

[10] H. Watanabe, The Architecture of Tokyo, Stuttgart \& London: Edition Axel Menges, 2001, p. 118.

[11] A. Waswo, Housing in Postwar Japan. A Social History, London: Routledge, 2002, p. 69-71.

[12] K. B. Hiesinger and F. Fischer, Japanese Design. A Survey since 1950, Ed. Philadelphia \& New York: Philadelphia Museum of Art \& Harry N. Abrams Inc., 1994, p.18.

[13] K. Tanabe, "Study of modular co-ordination in Japan," KokusaiKentiku, vol. 25, no. 1, p. 11, January 1958.

[14] C. Wendelken, "Japanese architectural culture in the 1950s," in Rebuilding Urban Japan after 1945, Ed. London: Palgrave Macmillan Ltd, 2003, p. 201.

[15] C. Wendelken, "Japanese architectural culture in the 1950s," in Rebuilding Urban Japan after 1945, C. Hein, J. Diefendorf, and I. Yorifusa, Ed. London: Palgrave Macmillan Ltd, 2003, pp. 209-211.

[16] M. Tafuri, L'Architettura moderna in Giappone, Bologna: Cappelli Editore, 1964, p. 75.

[17] E. Tempel and N. Nishimura, New Japanese Architecture, New York: Praeger, 1969, p. 23.

[18] H. W. Coaldrake, Architecture and Authority in Japan, London \& New York: Nissan Institute/Routledge Japanese Studies, 1996, pp.252-253.

[19] V. Barnett "The postwar period and a glimpse of the future-postwar prosperity and the construction industry," JA-Japan Architect, no. 139, pp. 82-83, March 1968.

[20] K. Inabe and S. Nakayama, Japanese Homes and Lifestyles. An Illustrated Journey through the History, Tokyo: Kodansha International, 2000, p. 112.

[21] K. Inabe and S. Nakayama, Japanese Homes and Lifestyles. An Illustrated Journey through the History, Tokyo: Kodansha International, 2000, p. 115.

[22] M. F. Ross, Beyond Metabolism: the New Japanese Architecture; New York: McGraw-Hill, 1978, pp. 39-40.

[23] J. Gottmann, Megalopolis: The Urbanized Northern Seaboard of the United States, Cambridge,The MIT Press, 1961.

[24] N. Glickman, The Management of the Japanese Urban System: Regional Development and Regional Planning in Postwar Japan; New York: Academic Press, 1979, p. 14.

[25] Bureau of Statistics of Japan, Historic Statistics Section. [Online]. Available. http://www.stat.go.jp.

[26] N. Glickman, The Management of the Japanese Urban System: Regional Development and Regional Planning in Postwar Japan, New York, Academic Press, 1979, p. 15.

[27] B. D. Steward, The Making of a Modern Japanese Architecture. 1868 to Present; Tokyo: Kodansha, 1987, p.178.

[28] U. Kultermann, Kenzo Tange: Architecture and Urban Design 19461969, New York: Praeger, 1970, pp. 162-164.

[29] Y. Masai, "Metropolitization in densely populated Asia: the case of Tokyo," in The Asian City: Processes of Development, Characteristics, and Planning, A. Dutt, F. Costa, and A. Noble, Ed. London: Kluwer Academic Publishers, 1994, pp. 121-124.

[30] G. Nitschke, "Transience and renewal in Japanese form," Kyoto Journal: Transience - Perspective on Asia, no. 50, p. 9, June 2002.

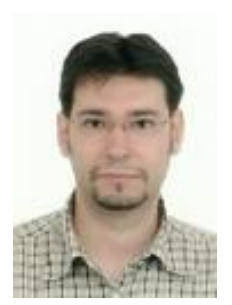

Raffaele Pernice is a licensed architect and lecturer in the Department of Urban Planning and Design at Xi'an Jiaotong - Liverpool University in Suzhou, China. He received a $\mathrm{PhD}$ in architecture from Waseda University in Tokyo, Japan and a Laurea in Architettura degree (BArch + MArch) from IUAV University of Venice, Italy.

From 2007 to 2009 he was post-doctoral research fellow at School of Engineering and Design, Department of Architecture, at Hosei University in Tokyo; subsequently he was assistant professor at AUST - Ajman University of Science and Technology - Department of Architectural Engineering in Ajman, United Arabs Emirates, and at Keimyung University - College of Architectural Studies in Daegu, South Korea.

Dr. Pernice research interests and activities range from practice to theory and history of architecture and urbanism, with a special focus on modern and post-modern planning and design theories and the urban development of East Asian cites. His researches and studies have been supported with scholarships and grants from universities and national and international institutions, such as the Japanese Government and MEXT (the Japanese Ministry of Education), MAE - the Italian Ministry of Foreign Affairs, MIUR - the Italian Ministry of University and Research, JSPS - the Japan Society for the Promotion of Sciences, among others. 